Check for updates

Cite this: RSC Adv., 2017, 7, 24040

\title{
Visible light-induced PET-RAFT polymerization of methacrylates with novel organic photocatalysts
}

\author{
Kai Tu, Tianchi Xu, Lifen Zhang, * Zhenping Cheng (D) * and Xiulin Zhu
}

Light-emitting diode (LED) technology in the visible spectrum holds great promise for photopolymerization because of its characteristic virtues such as low energy consumption, no ozone release, low heat generation, simple and safe operation, high performance, etc. In this work, two organic agents, 4methoxybenzaldehyde (PC1) and 2,4,6-tri-(p-methoxyphenyl) pyrylium tetrafluoroborate (PC2), were employed as the photocatalysts for the photoinduced electron transfer-reversible additionfragmentation chain transfer (PET-RAFT) polymerization under irradiation of various LED lights (purple, blue and white LEDs) at room temperature, using methyl methacrylate (MMA) as the model monomer and typical 2-cyanoprop-2-yl 1-dithionaphthalate (CPDN) as the RAFT agent. It has been found that the polymerization could be carried out smoothly with a wide range of wavelengths of visible light and could be extended to other methacrylates such as ethyl methacrylate (EMA) and $n$-butyl methacrylate ( $n$-BMA). In addition, the "living" feature of this polymerization system was demonstrated by its polymerization kinetics and was confirmed by a chain-extension experiment.

Received 16th March 2017 Accepted 23rd April 2017

DOI: $10.1039 / \mathrm{c} 7 \mathrm{ra03103c}$

rsc.li/rsc-advances external stimulus, light-emitting diodes (LED) in the visible spectrum is the most ideal stimulus due to its characteristic virtues such as low energy consumption, no ozone release, low heat generation, simple and safe operation, high performance. Now it has been successfully used in various LRP methods with controlled molecular and narrow molecular weight distribution under mild conditions. ${ }^{6}$

On the other hand, since Hawker and co-workers developed a kind of transition metal photoredox catalyst (e.g., fac$\left.\left[\operatorname{Ir}(\mathrm{ppy})_{3}\right]\right)$ for photoinduced ATRP, ${ }^{7}$ Boyer and co-workers established a highly efficient photoinduced electron transfer RAFT (PET-RAFT) polymerization using this kind of metal photoredox catalysts. ${ }^{8}$ Frustratingly, the resultant polymers are easily contaminated by the transition metal catalyst, and therefore limited its application fields (e.g., electronic materials) significantly. Therefore, organic photocatalyst is highly promising to solve the problem of PET-RAFT mentioned above. Now, some organic photocatalysts, such as methylene blue, fluorescein, rhodamine 6G, Nile red, eosin $\mathrm{Y}$, porphyrin compounds, chlorophyll a ( $\mathrm{Chl}$ a), and pheophorbide, were explored. ${ }^{9}$ In order to enrich the library of organic photocatalyst, in this work, by combination of both advantages of visible LED lights and PET-RAFT polymerization, the commercially available organic catalyst 4-methoxybenzaldehyde (PC1) and the synthesized 2,4,6-tri-( $p$-methoxyphenyl) pyrylium tetrafluoroborate (PC2) were used as the organic photocatalyst for the PET-RAFT polymerization of methacrylates under irradiation of visible LED lights at room temperature. The effect of solvent and wavelength of LED lights and polymerization kinetics was studied in detail.
Suzhou Key Laboratory of Macromolecular Design and Precision Synthesis, Jiangsu Key Laboratory of Advanced Functional Polymer Design and Application, State and Local Joint Engineering Laboratory for Novel Functional Polymeric Materials, Department of Polymer Science and Engineering, College of Chemistry, Chemical Engineering and Materials Science, Soochow University, Suzhou 215123, China. E-mail: chengzhenping@suda.edu.cn; zhanglifen@suda.edu.cn; Fax: +86-512-65882787 


\section{Experimental section}

\subsection{Materials}

Monomers, methyl methacrylate (MMA, 99+\%) purchased from Shanghai Chemical Reagents Co. Ltd. (Shanghai, China), ethyl methacrylate (EMA, 98+\%) and $n$-butyl methacrylate (n-BMA, 99\%) purchased from TCI (Shanghai, China) were removed the inhibitor by passing through a neutral alumina column before use. The RAFT agent 2-cyanoprop-2-yl 1-dithionaphthalate (CPDN) was prepared according to the method reported by the literature. ${ }^{\mathbf{1 0}}$ Tetrahydrofuran (THF, analytical reagent) purchased from Nanjing Chemical Reagent Co. 4-Methoxybenzaldehyde (PC1) and 4'-methoxyacetophenone were purchased from Univ-bio (Shanghai, China). Ethyl ether boron fluoride $\left(\mathrm{BF}_{3} \cdot \mathrm{Et}_{2} \mathrm{O}\right)$ was purchased from Innochem (Beijing, China). Toluene (analytical reagent), anisole (analytical reagent), $N, N$-dimethylformamide (DMF), 1,4-dioxane (analytical reagent), acetone (analytical reagent), dimethyl sulfoxide (DMSO), $\mathrm{N}, \mathrm{N}$-dimethylacetamide (DMAc, analytical reagent) were purchased from Chinasun Specialty Products Co. Ltd. and used as received unless mentioned.

\subsection{Synthesis of $2,4,6-$ tri-( $p$-methoxyphenyl) pyrylium tetrafluoroborate (PC2)}

The synthetic route of PC2 is shown in Scheme 1. Details are as follows: to a flask containing 4-methoxybenzaldehyde $(6.1 \mathrm{~mL}$, $50.3 \mathrm{mmol}, 1$ equiv.) and $p$-acetylanisole $(15.07 \mathrm{~g}, 100.4 \mathrm{mmol}, 2$ equiv.) was added $\mathrm{BF}_{3} \cdot \mathrm{Et}_{2} \mathrm{O}$ (15.0 mL, $121.5 \mathrm{mmol}, 2.4$ equiv.) dropwise over $5 \mathrm{~min}$. The solution was placed in an oil bath set to $100{ }^{\circ} \mathrm{C}$ for $2 \mathrm{~h}$. After cooled to room temperature, the crude material was diluted with acetone $(200 \mathrm{~mL})$ and $\mathrm{Et}_{2} \mathrm{O}(250 \mathrm{~mL})$

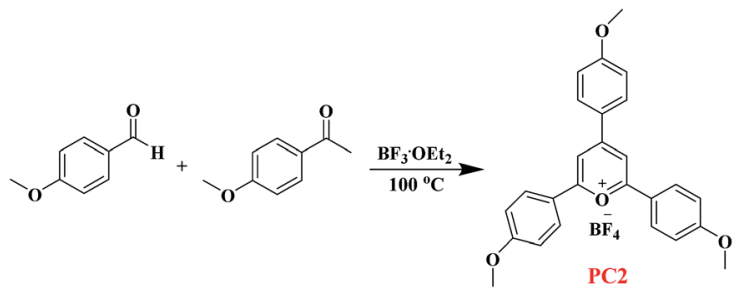

Scheme 1 The synthetic pathway of organic photocatalyst 2,4,6-tri( $p$-methoxyphenyl) pyrylium tetrafluoroborate (PC2).

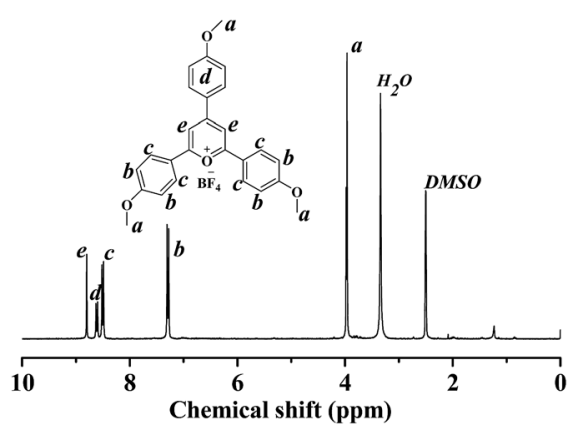

Fig. $1{ }^{1} \mathrm{H}$ NMR of the organic photocatalyst (PC2). and filtered to give a rust-colored solid. The solids were washed with warm acetone $(175 \mathrm{~mL})$ and dried under vacuum to give the pyrylium tetrafluoroborate as an orange solid (5.01 g, 20\% of yield). The structure of PC2 was analysed by ${ }^{1} \mathrm{H}$ NMR spectroscopy (Fig. 1), and its spectral matched that previously reported. ${ }^{\mathbf{1 1}}$

\subsection{Typical procedures for PET-RAFT polymerization}

A typical polymerization procedure with the molar ratio of $[\mathrm{MMA}]_{0}:[\mathrm{PC} 1]_{0}:[\mathrm{CPDN}]_{0}=400: 50: 1$ was described as follows. A mixture was obtained by adding CPDN (6.4 mg), MMA $(1.0 \mathrm{~mL}), \mathrm{PC} 1(0.14 \mathrm{~mL})$, and solvent (DMAc, $0.5 \mathrm{~mL})$ to a clean ampoule with a stir bar. The mixture was thoroughly bubbled with argon for $20 \mathrm{~min}$ to eliminate the dissolved oxygen, and then the ampoule was flame-sealed and irradiated under LED light with stirring at room temperature $\left(25^{\circ} \mathrm{C}\right)$, which was kept by a fanning. After the desire polymerization time, the ampoule was opened and the mixture was diluted by THF. After precipitation with plenty of petroleum ether in a glass, and standing overnight, it was filtered and dried in a vacuum oven at $40{ }^{\circ} \mathrm{C}$ until constant weight. The monomer conversion was determined by gravimetrically. The other procedures for PET-RAFT polymerization of MMA using PC2 as the organic photocatalyst were similar as that as described above.

\subsection{Characterization}

The number-average molecular weight $\left(M_{\mathrm{n}, \mathrm{GPC}}\right)$ and molecular weight distribution $\left(M_{\mathrm{w}} / M_{\mathrm{n}}\right)$ of the resultant polymers were determined by using a TOSOH HLC-8320 gel permeation chromatograph (GPC) equipped with a refractive-index detector $(\mathrm{TOSOH})$, using TSKgel guardcolumn SuperMP-N $(4.6 \times 20$ $\mathrm{mm})$ and two TSKgel SupermultiporeHZ-N $(4.6 \times 150 \mathrm{~mm})$ with measurable molecular weights ranging from $5 \times 10^{2}$ to $5 \times$ $10^{5} \mathrm{~g} \mathrm{~mol}^{-1}$. THF was used as the eluent at a flow rate of $0.6 \mathrm{~mL}$ $\min ^{-1}$ and $40{ }^{\circ} \mathrm{C}$. GPC samples were injected using a TOSOH plus autosampler and calibrated with PMMA standards purchased from TOSOH. ${ }^{1} \mathrm{H}$ NMR spectra were recorded on Bruker $300 \mathrm{MHz}$ nuclear magnetic resonance (NMR) instrument using $\mathrm{CDCl}_{3}$ as the solvent and tetramethylsilane (TMS) as the internal standard at ambient temperature.

\section{Results and discussion}

\subsection{Effect of solvent on the polymerization catalyzed by PC1}

Firstly, we investigated the commercially available 4-methoxybenzaldehyde (PC1) photocatalyst ${ }^{\mathbf{1 2}}$ for this PET-RAFT polymerization system for the first time. Subsequently, the effect of solvent including toluene, anisole, 1,4-dioxane, DMAc, and DMF on the PET-RAFT polymerization were studied under irradiation of white LED light at room temperature, and the results are shown in Table 1 . It can be seen that all the polymerizations were carried out smoothly and that relatively faster polymerization rate was observed in more polar solvents (e.g., DMAc, DMF) due to its basicity. ${ }^{12}$ Taking into account the molecular weight and molecular weight distribution of the 
Table 1 Effect of solvent on the PET-RAFT polymerization ${ }^{a}$

\begin{tabular}{llllll}
\hline Entry & Solvent & $\begin{array}{l}\text { Conv. } \\
(\%)\end{array}$ & $\begin{array}{l}M_{\mathrm{n}, \mathrm{th}^{b}}{ }^{b} \\
\left(\mathrm{~g} \mathrm{~mol} \mathrm{~mol}^{-1}\right)\end{array}$ & $\begin{array}{l}M_{\mathrm{n}, \mathrm{GPC}} \\
\left(\mathrm{g} \mathrm{mol} \mathrm{mol}^{-1}\right)\end{array}$ & $M_{\mathrm{w}} / M_{\mathrm{n}}$ \\
\hline 1 & None & 20.6 & 8200 & 13500 & 1.27 \\
2 & Toluene & 16.7 & 6700 & 12700 & 1.26 \\
3 & Anisole & 22.3 & 8900 & 15600 & 1.24 \\
4 & DMF & 27.6 & 11000 & 16300 & 1.62 \\
5 & DMAc & 24.4 & 9760 & 16610 & 1.21
\end{tabular}

${ }^{a}$ Polymerization condition: $R=[\mathrm{MMA}]_{0}:[\mathrm{PC} 1]_{0}:[\mathrm{CPDN}]_{0}=$ $400: 50: 1, V_{\mathrm{MMA}}=1.0 \mathrm{~mL}, m_{\mathrm{CPDN}}=6.4 \mathrm{mg}, V_{\mathrm{PC} 1}=0.14 \mathrm{~mL}$; temperature $=25{ }^{\circ} \mathrm{C}, V_{\text {solvent }}=0.5 \mathrm{~mL}$, under irradiation of white LED $\left(\lambda_{\max }=440,540 \mathrm{~nm}, 1.2 \mathrm{~mW} \mathrm{~cm}{ }^{-2}\right)$, time $=60 \mathrm{~h} .{ }^{b} M_{\mathrm{n}, \mathrm{th}}=$ $\left([\mathrm{M}]_{\mathrm{o}} /[\mathrm{CPDN}]_{\mathrm{o}}\right) \times M_{\mathrm{w}, \mathrm{MMA}} \times$ conv. $\%$.

Table 2 Effect of the wavelength of LED on the PET-RAFT polymerization $^{a}$

\begin{tabular}{llllll}
\hline Entry & $\begin{array}{l}\text { Time } \\
(\mathrm{h})\end{array}$ & $\begin{array}{l}\text { Conv. } \\
(\%)\end{array}$ & $\begin{array}{l}M_{\mathrm{n}, \mathrm{th}}{ }^{e} \\
\left.(\mathrm{~g} \mathrm{~mol})^{-1}\right)\end{array}$ & $\begin{array}{l}M_{\mathrm{n}, \mathrm{GPC}} \\
\left(\mathrm{g} \mathrm{mol}^{-1}\right)\end{array}$ & $M_{\mathrm{w}} / M_{\mathrm{n}}$ \\
\hline $1^{b}$ & 48 & 13.0 & 5200 & 12200 & 1.32 \\
$2^{b}$ & 72 & 56.6 & 22600 & 30600 & 1.16 \\
$3^{c}$ & 48 & 49.2 & 19700 & 25000 & 1.23 \\
$4^{c}$ & 72 & 95.7 & 38200 & 45300 & 1.26 \\
$5^{d}$ & 48 & 53.5 & 21400 & 27400 & 1.11 \\
$6^{d}$ & 72 & 96.6 & 38600 & 46400 & 1.15
\end{tabular}

${ }^{a}$ Polymerization condition: $R=[\mathrm{MMA}]_{0}:[\mathrm{PC} 1]_{0}:[\mathrm{CPDN}]_{0}=$ $400: 50: 1, V_{\mathrm{MMA}}=1.0 \mathrm{~mL}, V_{\mathrm{PC} 1}=0.14 \mathrm{~mL}, m_{\mathrm{CPDN}}=6.4 \mathrm{mg}, V_{\mathrm{DMAc}}$ $=0.5 \mathrm{~mL}$, temperature $=25{ }^{\circ} \mathrm{C} .{ }^{b}$ White LED $\left(\lambda_{\max }=440,540 \mathrm{~nm}\right.$, $\left.1.2 \mathrm{~mW} \mathrm{~cm}^{-2}\right) .{ }^{c}$ Blue LED $\left(\lambda_{\max }=464 \mathrm{~nm}, 0.8 \mathrm{~mW} \mathrm{~cm}^{-2}\right) .{ }^{d}$ Purple LED $\left(\lambda_{\max }=391 \mathrm{~nm}, 0.8 \mathrm{~mW} \mathrm{~cm}{ }^{-2}\right) .{ }^{e} M_{\mathrm{n}, \mathrm{th}}=\left([\mathrm{M}]_{0} /[\mathrm{CPDN}]_{0}\right) \times$ $M_{\mathrm{w}, \mathrm{MMA}} \times$ conv. $\%$.

resultant polymers, DMAc (entry 5 in Table 1 ) as the solvent additionally preferred to be used.

\subsection{Effect of the wavelength of LED and the amount of organic photocatalyst on the polymerization}

In order to investigate the effect of wavelength of LED on the PET-RAFT polymerization at room temperature, we kept the optimized polymerization conditions constant and changed the

Table 3 Effect of the amount of organic photocatalyst on the PETRAFT polymerization ${ }^{a}$

\begin{tabular}{llllll}
\hline Entry & $R$ & $\begin{array}{l}\text { Conv. } \\
(\%)\end{array}$ & $\begin{array}{l}M_{\mathrm{n}, \mathrm{th}}{ }^{b} \\
\left(\mathrm{~g} \mathrm{~mol}^{-1}\right)\end{array}$ & $\begin{array}{l}M_{\mathrm{n}, \mathrm{GPC}} \\
\left(\mathrm{g} \mathrm{mol}^{-1}\right)\end{array}$ & $M_{\mathrm{w}} / M_{\mathrm{n}}$ \\
\hline 1 & $400: 20: 1$ & 30.2 & 12100 & 19500 & 1.25 \\
2 & $400: 30: 1$ & 32.3 & 12900 & 20400 & 1.24 \\
3 & $400: 40: 1$ & 43.1 & 17200 & 25500 & 1.18 \\
4 & $400: 50: 1$ & 53.7 & 21500 & 28200 & 1.11 \\
5 & $400: 200: 1$ & 63.7 & 25500 & 38500 & 1.16
\end{tabular}

${ }^{a}$ Polymerization condition: $R=[\mathrm{MMA}]_{0}:[\mathrm{PC} 1]_{0}:[\mathrm{CPDN}]_{0}, V_{\mathrm{MMA}}=1.0$ $\mathrm{mL}, V_{\mathrm{PC} 1}=0.14 \mathrm{~mL}, m_{\mathrm{CPDN}}=6.4 \mathrm{mg}, V_{\mathrm{DMAc}}=0.5 \mathrm{~mL}$, temperature $=$ $25{ }^{\circ} \mathrm{C}$, white LED $\left(\lambda_{\max }=440,540 \mathrm{~nm}, 1.2 \mathrm{~mW} \mathrm{~cm}{ }^{-2}\right)$, time $=72 \mathrm{~h}$. ${ }^{b} M_{\mathrm{n}, \mathrm{th}}=\left([\mathrm{M}]_{\mathrm{o}} /[\mathrm{I}]_{\mathrm{o}}\right) \times M_{\mathrm{n}, \mathrm{MMA}} \times$ conv. $\%$. wavelength of LED (purple LED, blue LED and white LED). As shown in Table 2, the polymerization could be carried out successfully in all cases although the polymerization rate changed with the wavelength, which increased with decrease of wavelength. For example, the monomer conversion was 56.6\%, $95.7 \%$ and $96.6 \%$ for the case under irradiation of purple, blue and white LED light, respectively. This is contributed to the fact that higher energy for the shorter wavelength of LED light. In addition, the effect of the amount of PC1 on the polymerization was also investigated, and the results are shown in Table 3. It can be seen that increasing the amount of catalyst enhanced the polymerization rate as expected.

\subsection{Kinetics of the polymerization catalyzed by PC1 under irradiation of different light}

In order to further investigate the detailed polymerization behaviors under various wavelength of LED, the polymerization kinetics of MMA was conducted with the molar ratio of $[\mathrm{MMA}]_{0}:[\mathrm{PC} 1]_{0}:[\mathrm{CPDN}]_{0}=400: 50: 1$ under irradiation of white LED, blue LED and purple LED, respectively. Fig. 2(A) shows the kinetic plots of $\ln \left([\mathrm{M}]_{0} /[\mathrm{M}]\right)$ versus time. The firstorder polymerization kinetics was observed in all cases, which indicating a constant concentration of propagating radicals during these polymerization processes. It should be noted that induction period of the polymerization under blue LED $(17 \mathrm{~h})$ and purple LED $(15 \mathrm{~h})$ is much shorter than that under white
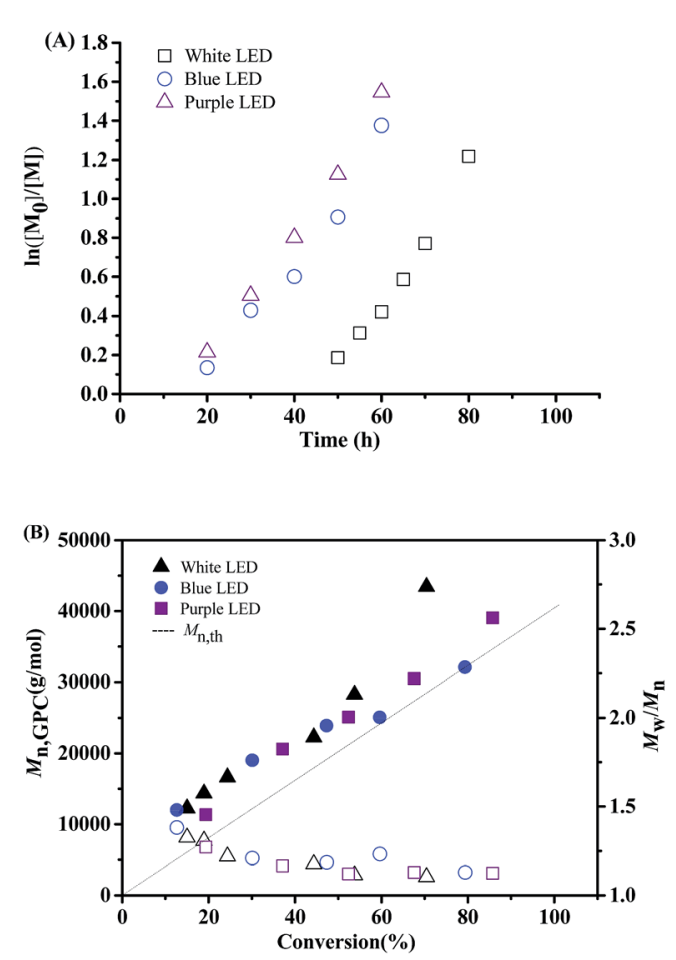

Fig. $2 \ln \left([\mathrm{M}]_{0} /[\mathrm{M}]\right)$ as a function of time $(\mathrm{A})$ and evolution of numberaverage molecular weight $\left(M_{n, G P C}\right)$ and molecular weight distribution $\left(M_{w} / M_{n}\right)$ versus conversion (B) under irradiation of different LED lights. Polymerization conditions: $R=[\mathrm{MMA}]_{0}:[\mathrm{PC} 1]_{0}:[\mathrm{CPDN}]_{0}=$ $400: 50: 1, V_{M M A}=1.0 \mathrm{~mL}, V_{\mathrm{PC} 1}=0.14 \mathrm{~mL}, m_{\mathrm{CPDN}}=6.4 \mathrm{mg}, V_{\mathrm{DMAC}}=$ $0.5 \mathrm{~mL}$, temperature $=25^{\circ} \mathrm{C}$. 
LED (46 h). Fig. 2(B) shows the evolution of $M_{\mathrm{n}, \mathrm{GPC}}$ and $M_{\mathrm{w}} / M_{\mathrm{n}}$ versus monomer conversion, and it can be seen that the molecular weights increased linearly with monomer conversion while keeping narrow molecular weight distributions. All these results indicated the "living" features of the PET-RAFT polymerization at room temperature.

\subsection{PET-RAFT polymerization catalyzed by PC2}

As reported by the reference, 2,4,6-tri-( $p$-methoxyphenyl) pyrylium tetrafluoroborate (PC2) is a good organic photocatalyst for cationic polymerization. ${ }^{13}$ In this work, we employed it as the photocatalyst for the PET-RAFT polymerization, and the results are shown in Table 4 . The polymerization could be carried out under irradiation of white, blue and purple LED lights. In order to investigate the potential interference with classical photoRAFT (iniferter) initiation, ${ }^{\mathbf{1 4}}$ we also carried out the control experiments in the absence of photocatalyst PC2 under blue and purple LED lights. The results are listed in entries 8-11 in Table 4. It can be seen that an enhanced polymerization rate for the photocatalyst was observed. For example, monomer conversion increased from $39.5 \%$ (entry 11 ) in the absence of photocatalyst to $59.2 \%$ (entry 7 ) for the case of photocatalyst PC2 under purple LED light. These results indicated that classical photoRAFT (iniferter) initiation actually existed in the polymerization system; however, the addition of photocatalyst could enhance the polymerization rate significantly. From the GPC results, the resultant polymers are well-controlled with narrow molecular weight distributions except for that (entries 2 and 3) under irradiation of white LED light, indicating that PC2 can also serve as a good candidate for the PET-RAFT polymerization. In order to explain the experimental phenomenon, we tested the absorption spectrum of PC2 (Fig. 3). It can be seen that the emission wavelengths of purple and blue LED lights are within the range of absorption wavelength of PC2, which facilitated to achieve high efficiency of photocatalyst. ${ }^{15}$

Table 4 Effect of the wavelength of LED on the polymerization in the presence/absence of PC2

\begin{tabular}{llllll}
\hline Entry & $\begin{array}{l}\text { Time } \\
(\mathrm{h})\end{array}$ & $\begin{array}{l}\text { Conv. } \\
(\%)\end{array}$ & $\begin{array}{l}M_{\mathrm{n}, \mathrm{th}}^{\mathrm{f}} \\
\left(\mathrm{g} \mathrm{mol}^{-1}\right)\end{array}$ & $\begin{array}{l}M_{\mathrm{n}, \mathrm{GPC}} \\
\left(\mathrm{g} \mathrm{mol}^{-1}\right)\end{array}$ & $M_{\mathrm{w}} / M_{\mathrm{n}}$ \\
\hline $1^{\mathrm{a}}$ & 24 & - & - & - & - \\
$2^{\mathrm{a}}$ & 48 & 9.1 & 3600 & 3900 & 1.54 \\
$3^{\mathrm{a}}$ & 72 & 35.5 & 14200 & 21300 & 1.62 \\
$4^{\mathrm{b}}$ & 24 & 23.0 & 9200 & 15100 & 1.35 \\
$5^{\mathrm{b}}$ & 48 & 47.3 & 18900 & 26800 & 1.36 \\
$6^{\mathrm{c}}$ & 24 & 30.1 & 12000 & 19500 & 1.24 \\
$7^{\mathrm{c}}$ & 48 & 59.2 & 23700 & 30000 & 1.23 \\
$8^{\mathrm{d}}$ & 24 & 12.7 & 5400 & 8100 & 1.15 \\
$9^{\mathrm{d}}$ & 48 & 34.2 & 14000 & 18900 & 1.26 \\
$10^{\mathrm{e}}$ & 24 & 17.4 & 7200 & 13600 & 1.24 \\
$11^{\mathrm{e}}$ & 48 & 39.5 & 16100 & 23300 & 1.29
\end{tabular}

Polymerization condition: ${ }^{\mathrm{a}, \mathrm{b}, \mathrm{c}} R=[\mathrm{MMA}]_{0}:[\mathrm{PC} 2]_{0}:[\mathrm{CPDN}]_{0}=$ $400: 0.5: 1, V_{\mathrm{MMA}}=1.0 \mathrm{~mL}, m_{\mathrm{PC} 2}=5.7 \mathrm{mg}, m_{\mathrm{CPDN}}=6.4 \mathrm{mg}, V_{\mathrm{DMAC}}$ $=0.5 \mathrm{~mL} .{ }^{\mathrm{a}}$ White LED $\left(\lambda_{\max }=440,540 \mathrm{~nm}, 1.2 \mathrm{~mW} \mathrm{~cm}^{-2}\right) .{ }^{\mathrm{b}, \mathrm{d}}$ Blue $\operatorname{LED}\left(\lambda_{\max }=464 \mathrm{~nm}, 0.8 \mathrm{~mW} \mathrm{~cm}{ }^{-2}\right) .{ }^{\mathrm{c}, \mathrm{e}}$ Purple LED $\left(\lambda_{\max }=391 \mathrm{~nm}\right.$, $\left.0.8 \mathrm{~mW} \mathrm{~cm}{ }^{-2}\right) .{ }^{\mathrm{d}, \mathrm{e}} R=[\mathrm{MMA}]_{0}:[\mathrm{CPDN}]_{0}=400: 1, V_{\mathrm{MMA}}=1.0 \mathrm{~mL}$, $m_{\mathrm{CPDN}}=6.4 \mathrm{mg}, V_{\mathrm{DMAc}}=0.5 \mathrm{~mL} .{ }^{\mathrm{f}} M_{\mathrm{n}, \mathrm{th}}=\left([\mathrm{M}]_{0} /[\mathrm{CPDN}]_{0}\right) \times M_{\mathrm{w}, \mathrm{MMA}}$ $\times$ conv. $\%$. ${ }^{\mathrm{a}-\mathrm{e}}$ Temperature $=25{ }^{\circ} \mathrm{C}$.

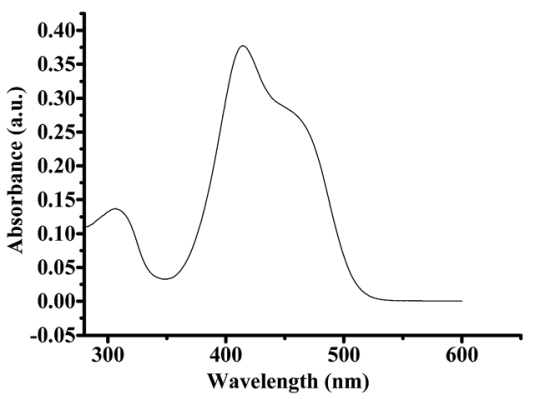

Fig. 3 UV-vis absorption spectrum of the synthetic photocatalyst PC2.
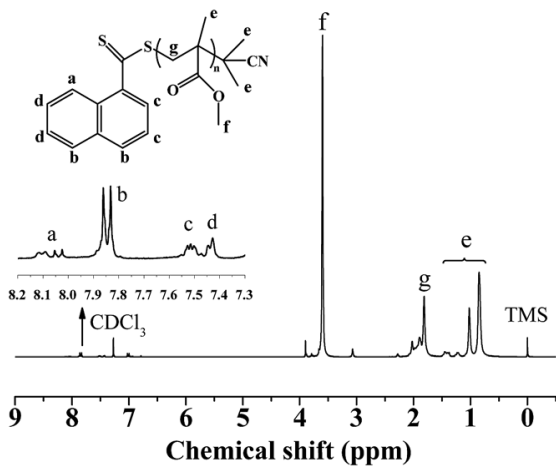

Fig. $4{ }^{1} \mathrm{H}$ NMR spectrum of the resultant PMMA catalysed by PC1 with $\mathrm{CDCl}_{3}$ as solvent.

\subsection{End analysis, chain extension and versatility for other monomers}

The chain-end of the resultant PMMA, catalysed by PC1, was analyzed by ${ }^{1} \mathrm{H}$ NMR spectroscopy, as shown in Fig. 4 . The chemical shifts at $\delta=0.8-1.2 \mathrm{ppm}$ were corresponded to methyl protons of the PMMA repeat units and naphthalene moieties in CPDN; and the chemical shifts at $\delta=7.4-8.1 \mathrm{ppm}$ were corresponded to the aromatic protons of the naphthalene units in $\mathrm{CPDN},{ }^{\mathbf{1 6}}$ which indicated that the CPDN moieties were

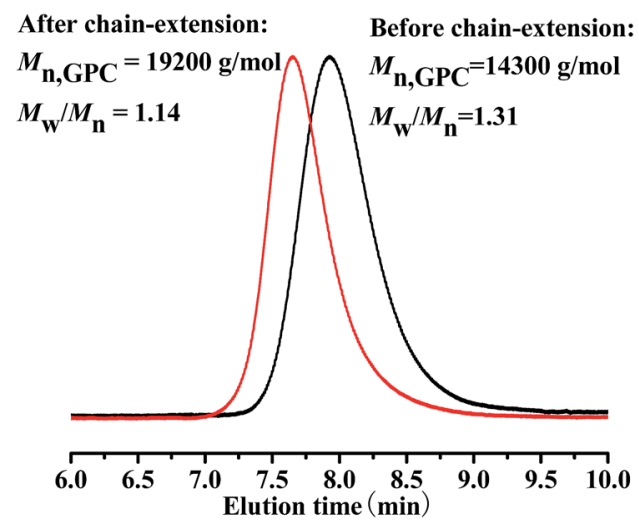

Fig. 5 GPC traces of before and after chain extension using random polymer PMMA as the macro-RAFT agent $\left(M_{n, G P C}=14300 \mathrm{~g} \mathrm{~mol}^{-1}\right.$, $\left.M_{\mathrm{w}} / M_{\mathrm{n}}=1.31\right)$. Polymerization conditions: $[\mathrm{MMA}]_{0}:[\mathrm{PC} 1]_{0}:[\mathrm{CPDN}]_{0}$ $=400: 50: 1, V_{\mathrm{MMA}}=1.0 \mathrm{~mL}, V_{\mathrm{PC} 1}=0.14 \mathrm{~mL}$, temperature $=25^{\circ} \mathrm{C}$, $V_{\text {DMAC }}=0.5 \mathrm{~mL}$, under irradiation of purple LED $(391 \mathrm{~nm}, 0.8 \mathrm{~mW}$ $\mathrm{cm}^{-2}$ ). 
Table 5 Versatility for other monomers catalyzed by PC1 and $\mathrm{PC}^{a}$

\begin{tabular}{llllll}
\hline Entry & Catalyst & Monomer & Conv. $(\%)$ & $M_{\mathrm{n}, \mathrm{th}}{ }^{d}\left(\mathrm{~g} \mathrm{~mol}^{-1}\right)$ & $M_{\mathrm{n}, \mathrm{GPC}}\left(\mathrm{g} \mathrm{mol}{ }^{-1}\right)$ \\
\hline $1^{b}$ & PC1 & EMA & 44.1 & 20100 & 26800 \\
$2^{b}$ & PC1 & $n$-BMA & 39.7 & 22500 & 30700 \\
$3^{c}$ & PC2 & EMA & 46.3 & 21100 & 28300 \\
$4^{c}$ & PC2 & $n$-BMA & 43.6 & 24800 & 31400
\end{tabular}

${ }^{a}$ Polymerization conditions: under irradiation of blue LED $\left(\lambda_{\max }=464 \mathrm{~nm}, 0.8 \mathrm{~mW} \mathrm{~cm}{ }^{-2}\right)$, temperature $=25{ }^{\circ} \mathrm{C}$, time $=48 \mathrm{~h} .{ }^{b} R=$ $[\text { monomer }]_{0}:[\mathrm{PC} 1]_{0}:[\mathrm{CPDN}]_{0}=400: 50: 1 .{ }^{c} R=[\mathrm{monomer}]_{0}:[\mathrm{PC} 2]_{0}:[\mathrm{CPDN}]_{0}=400: 0.5: 1 .{ }^{d} M_{\mathrm{n}, \mathrm{th}}=\left([\mathrm{M}]_{\mathrm{o}} /[\mathrm{CPDN}]_{0}\right) \times M_{\mathrm{w}, \mathrm{MMA}} \times \mathrm{conv} . \%$.

attached to the polymer chain-end successfully. In order to further verify the end functionality of the resultant PMMA, a chain extension experiment was conducted with fresh MMA monomer using PMMA $\left(M_{\mathrm{n}, \mathrm{GPC}}=14300 \mathrm{~g} \mathrm{~mol}^{-1}, M_{\mathrm{w}} / M_{\mathrm{n}}=\right.$ 1.31) as the macro-RAFT agent. From Fig. 5, it was found that the $M_{\mathrm{n}, \mathrm{GPC}}$ increased to $19200 \mathrm{~g} \mathrm{~mol}^{-1}\left(M_{\mathrm{w}} / M_{\mathrm{n}}=1.14\right)$ after chain extension. Based on the above experimental results, we can draw the conclusion that polymeric product has a high degree of chain-end functionality, further verifying the "living" features of this polymerization system.

In order to investigate the versatility of the polymerization system, EMA and $n$-BMA were used as the monomers to conduct PET-RAFT polymerization. The results are shown in Table 5. It can be seen that the polymerization system is also suitable for EMA and $n$-BMA, verifying by the controlled molecular weights and molecular weight distributions of the resultant polymers in the cases of both PC1 and PC2.

\section{Conclusions}

The two novel organic agents 4-methoxybenzaldehyde and 2,4,6-tri-( $p$-methoxyphenyl) pyrylium tetrafluoroborate were explored as the photocatalysts for the PET-RAFT polymerization of methacrylates (e.g., MMA, EMA and n-BMA) under irradiation of LED lights successfully for the first time. Through the experiments, we investigated the effect of the types of solvents and lights on the polymerization and screened the optimal polymerization conditions. It was found that DMAc as the solvent can improve the polymerization rate and controllability due to the better solubility for the polymerization system. In addition, the polymerization was well-controlled under irradiation of blue and purple LED lights.

\section{Acknowledgements}

The financial support from the Nature Science Key Basic Research of Jiangsu Province for Higher Education (No. 16KJA150003), the National Natural Science Foundation of China (No. 21674071) and the Project Funded by the Priority Academic Program Development of Jiangsu Higher Education Institutions (PAPD) is gratefully acknowledged.

\section{Notes and references}

1 (a) M. K. Georges, R. P. N. Veregin, P. M. Kazmaier and G. K. Hamer, Macromolecules, 1993, 26, 2987-2988; (b)
C. J. Hawker, A. W. Bosman and E. Harth, Chem. Rev., 2001, 101, 3661-3688; (c) V. Sciannamea, R. Jérôme and C. Detrembleur, Chem. Rev., 2008, 108, 1104-1126; (d) J. Nicolas, Y. Guillaneuf, C. Lefay, D. Bertin, D. Gigmes and B. Charleux, Prog. Polym. Sci., 2013, 38, 63-235; (e) J. C. Scaiano, T. J. Connolly, N. Mohtat and C. N. Pliva, Can. J. Chem., 1997, 75, 92-97; (f) S. Hu, J. H. Malpert, X. Yang and D. C. Neckers, Polymer, 2000, 41, 445-452; $(g)$ A. Goto, J. C. Scaiano and L. Maretti, Photochem. Photobiol. Sci., 2007, 6, 833-835; (h) D. L. Versace, Y. Guillaneuf, D. Bertin, J. P. Fouassier, J. Lalevee and D. Gigmes, Org. Biomol. Chem., 2011, 9, 2892-2898; (i) J. Morris, S. Telitel, K. E. Fairfull-Smith, S. E. Bottle, J. Lalevee, J. L. Clement, Y. Guillaneuf and D. Gigmes, Polym. Chem., 2015, 6, 754-763. 2 (a) M. Kato, M. Kamigaito, M. Sawamoto and T. Higashimura, Macromolecules, 1995, 28, 1721-1723; (b) J. S. Wang and K. Matyjaszewski, J. Am. Chem. Soc., 1995, 117, 5614-5615; (c) K. Matyjaszewski and J. H. Xia, Chem. Rev., 2001, 101, 2921-2990; (d) M. Kamigaito, T. Ando and M. Sawamoto, Chem. Rev., 2001, 101, 3689-3746; (e) L. J. Bai, L. F. Zhang, Z. P. Cheng and X. L. Zhu, Polym. Chem., 2012, 3, 2685-2697; (f) W. W. He, H. J. Jiang, L. F. Zhang, Z. P. Cheng and X. L. Zhu, Polym. Chem., 2013, 4, 2919-2938; $(g)$ Z. B. Guan and B. Smart, Macromolecules, 2000, 33, 6904-6906; (h) X. W. Jiang, J. Wu, L. F. Zhang, Z. P. Cheng and X. L. Zhu, Macromol. Rapid Commun., 2014, 35, 1879-1885; (i) M. Ciftci, M. A. Tasdelen and Y. Yagci, Polym. Chem., 2014, 5, 600-606; (j) X. Pan, N. Malhotra, J. Zhang and K. Matyjaszewski, Macromolecules, 2015, 48, 6948-6954; (k) X. W. Jiang, L. F. Zhang, Z. P. Cheng and X. L. Zhu, Macromol. Rapid Commun., 2016, 37, 1337-1343; (l) B. J. Zhang, L. Yao, X. D. Liu, L. F. Zhang, Z. P. Cheng and X. L. Zhu, ACS Sustainable Chem. Eng., 2016, 4, 7066-7073; (m) X. D. Liu, L. F. Zhang, Z. P. Cheng and X. L. Zhu, Polym. Chem., 2016, 7, 689-700; (n) Z. C. Huang, Y. Gu, X. D. Liu, L. F. Zhang, Z. P. Cheng and X. L. Zhu, Macromol. Rapid Commun., 2016, DOI: 10.1002/marc.201600461.

3 (a) J. Chiefari, Y. Chong, F. Ercole, J. Krstina, J. Jeffery, T. P. Le, R. T. Mayadunne, G. F. Meijs, C. L. Moad and G. Moad, Macromolecules, 1998, 31, 5559-5562; (b) C. Boyer, V. Bulmus, T. P. Davis, V. Ladmiral, J. Q. Liu and S. Perrier, Chem. Rev., 2009, 109, 5402-5436; (c) D. J. Keddie, Chem. Soc. Rev., 2014, 43, 496-505; (d) B. Wenn, M. Conradi, A. D. Carreiras, D. M. Haddleton and T. Junkers, Polym. Chem., 2014, 5, 3053-3060; (e) 
R. K. Bai, Y. Z. You and C. Y. Pan, Macromol. Rapid Commun., 2001, 22, 315-319; $(f)$ L. Lu, H. J. Zhang, N. F. Yang and Y. L. Cai, Macromolecules, 2006, 39, 3770-3776; $(g)$ Z. Li, W. J. Chen, Z. B. Zhang, L. F. Zhang, Z. P. Cheng and X. L. Zhu, Polym. Chem., 2015, 6, 1937-1943; $(h)$ Z. Li, W. J. Chen, L. F. Zhang, Z. P. Cheng and X. L. Zhu, Polym. Chem., 2015, 6, 5030-5035.

4 (a) A. J. D. Magenau, N. C. Strandwitz, A. Gennaro and K. Matyjaszewski, Science, 2011, 332, 81-84; (b) N. Bortolamei, A. A. Isse, A. J. D. Magenau, A. Gennaro and K. Matyjaszewski, Angew. Chem., Int. Ed., 2011, 50, 1139111394; (c) Y. Kwak and K. Matyjaszewski, Macromolecules, 2010, 43, 5180-5183.

5 (a) T. Otsu and M. Yoshida, Macromol. Rapid Commun., 1982, 3, 127-132; (b) L. F. Fan, H. J. Jiang, L. F. Zhang, Z. P. Cheng and X. L. Zhu, RSC Adv., 2015, 5, 31657-31663.

6 (a) S. Shanmugam, J. Xu and C. Boyer, J. Am. Chem. Soc., 2015, 137, 9174-9185; (b) Y. G. Zhao, M. M. Yu, S. L. Zhang, Y. C. Liu and X. F. Fu, Macromolecules, 2014, 47, 6238-6245; (c) X. L. Miao, W. Zhu, Z. B. Zhang, W. Zhang, X. L. Zhu and J. Zhu, Polym. Chem., 2014, 5, 551-557; (d) X. L. Miao, J. J. Li, Z. B. Zhang, Z. P. Cheng, W. Zhang, J. Zhu and X. L. Zhu, Polym. Chem., 2014, 5, 46414648; (e) X. D. Liu, L. F. Zhang, Z. P. Cheng and X. L. Zhu, Polym. Chem., 2016, 7, 3576-3588; (f) X. D. Liu, L. F. Zhang, Z. P. Cheng and X. L. Zhu, Chem. Commun., 2016, 52, 10850-10853; (g) Z. C. Huang, L. F. Zhang, Z. P. Cheng and X. L. Zhu, Polymers, 2017, 9, 4; $(h)$ T. G. McKenzie, Q. Fu, M. Uchiyama, K. Satoh, J. Xu, C. Boyer, M. Kamigaito and G. G. Qiao, Adv. Sci., 2016, 3, 1500394.
7 B. P. Fors and C. J. Hawker, Angew. Chem., Int. Ed., 2012, 51, 8850-8853.

8 (a) J. Xu, K. Jung, A. Atme, S. Shanmugam and C. Boyer, J. Am. Chem. Soc., 2014, 136, 5508-5519; (b) J. Xu, K. Jung and C. Boyer, Macromolecules, 2014, 47, 4217-4229.

9 (a) S. Shanmugam, J. Xu and C. Boyer, J. Am. Chem. Soc., 2015, 137, 9174-9185; (b) S. Shanmugam, J. Xu and C. Boyer, Chem. Sci., 2015, 6, 1341-1349; (c) J. Xu, S. Shanmugam, H. T. Duong and C. Boyer, Polym. Chem., 2015, 6, 5615-5624; (d) S. Shanmugam, J. Xu and C. Boyer, Angew. Chem., Int. Ed., 2016, 55, 1036-1040; (e) S. Shanmugam, J. Xu and C. Boyer, Polym. Chem., 2016, 7, 6437-6449.

10 J. Zhu, X. L. Zhu, Z. P. Cheng, F. Liu and J. M. Lu, Polymer, 2002, 43, 7037-7042.

11 M. Martiny, E. Steckhan and T. Esch, Chem. Ber., 1993, 126, 1671-1682.

12 E. Arceo, E. Montroni and P. Melchiorre, Angew. Chem., Int. Ed., 2014, 53, 12064-12068.

13 Q. Michaudel, V. Kottisch and B. P. Fors, Angew. Chem., Int. Ed., 2017, DOI: 10.1002/anie.201701425.

14 (a) T. G. McKenzie, Q. Fu, E. H. H. Wong, D. E. Dunstan and G. G. Qiao, Macromolecules, 2015, 48, 3864-3872; (b) B. Wenn and T. Junkers, Macromolecules, 2016, 49, 6888-6895.

15 N. Corrigan, S. Shanmugam, J. Xu and C. Boyer, Chem. Soc. Rev., 2016, 45, 6165-6212.

16 (a) L. J. Bai, L. F. Zhang, J. L. Pan, J. Zhu, Z. P. Cheng and X. L. Zhu, Macromolecules, 2013, 46, 2060-2066; (b) J. L. Pan, L. F. Zhang, L. J. Bai, Z. B. Zhang, H. Chen, Z. P. Cheng and X. L Zhu, Polym. Chem., 2013, 4, 2876-2883. 